\title{
Toxicity of Sewage from Industrial Wastewater Tratment Plants
}

\author{
Andrzej Butarewicz ${ }^{1 *}$, Ewelina Wrzaszcz, Stanisław Rosochacki ${ }^{1}$ \\ 1 Department of Chemistry, Biology and Biotechnology, Faculty of Civil and Environmental Engineering, \\ Bialystok University of Technology, ul. Wiejska 45 E, 15-351 Bialystok, Poland \\ * Corresponding author's e-mail: a.butarewicz@pb.edu.pl
}

\begin{abstract}
The aim of this work was to evaluate the ecotoxicity of the waste water from chosen sewage treatment plants. Microtox M500 and Aliivibrio fischeri luminescent bacteria were used for the assessment of toxicity as well as acute tests using aquatic organisms: Daphnia magna crustacea and Chironomus tentans larvae. The performed ecotoxicological tests showed different ranges of sensitivity of living organisms when it comes to the individual types of industrial sewage. The Aliivibrio fischeri bacteria turned out to be the most sensitive bioindicator. In addition, the inclusion of toxicity tests in a wastewater management system in industrial plants will allow the elimination of toxic sewage disposal into the surface water and soil.
\end{abstract}

Keywords: industrial sewage, bioassey, acute toxicity tests, Microtox

\section{INTRODUCTION}

The development of industrial sectors and the complex technologies used in them are the main cause of increasing amounts of toxic chemicals and constitute a source of dangerous post-production sewage. Industrial sewage, depending on the sector in which they were created, may be characterized by a variable content of onerous chemical compounds, including more and more substances with unidentified properties. Their penetration to water receivers or soils poses a serious threat to the health and life of the organisms living in them. Toxic compounds, including heavy metals (eg lead, cadmium, mercury, zinc, chromium), pesticides, polycyclic aromatic hydrocarbons (PAHs), aromatic amines, nitrosamine, polychlorinated biphenyls (PCB), polychlorinated dibenzodioxins and dibenzofurans (PCDD/F), nonylphenols (NPE) and nonylphenethylethoxylates (NPEO), trichloromethanes and radioactive substances constitute a special group of pollutants found in the industrial sewage. Environmental tests conducted in recent years have revealed many new undiagnosed chemicals [Richardson and Kimura 2017; Richardson and Ternes 2014,
2011]. Many of these contaminants are drug derivatives from the pharmaceutical industry. The above-mentioned impurities have at least one of the following properties: carcinogenic, mutagenic, teratogenic, or capacity for bioaccumulation in the human and animal food chain. Many toxic impurities present in wastewater as refractive compounds are not removed in classic wastewater treatment processes.

In Poland, industrial wastewater toxicity control covers only the analysis of chemicals. The results obtained from this type of research are often incomplete, as it usually covers the determination of dangerous substances defined only in the applicable legal acts. Routine chemical analyses do not take into account newly synthesized compounds, which can enter the environment and have a toxic effect on living organisms.

Bioindication analyses are based on using the reactions of living organisms characteristic for a given level of trophic chain, which enable to assess the toxicity of environmental samples (sewage, water, soils). In addition to the classic toxicity tests, the Microtox system is currently the most widespread method for carrying out bioindication analyses. The most important criteria that 
contributed to its widespread use for determining the toxicity of sewage samples are: easy handling, speed, economy and high sensitivity of bioindicators to toxic substances.

\section{MATERIALS AND METHODS}

\section{The origin of the tested wastewater}

The names of research facilities were not disclosed due to with of the management bodies to maintain data privacy. Part of the analyzed sewage samples came from a newly commissioned (first in central Poland) industrial sewage treatment plant in Zgierz. It enables comprehensive cleaning of all types of wastewater, including sewage contaminated with heavy metals (Figure 1). Wastewater from various industries is transported to the treatment plant for purification. The type of treated sewage determines the selection of the chemical substance used in the purification process, which can only be of organic origin.

The wastewater samples were obteined from seven sources (table 1). The first three kinds of samples were obtained from:

- galvanic industry - dealing with the application of more durable coatings for the products made of less noble materials

- mining industry - dealing with the acquisition of natural resources (e.g. mining of coal, metal ores, crude oil, quarries, etc.) and adapting them to the needs of people

- metallurgical industry - the most important branch of the Polish industry dealing in the extraction of ores from the ground, which are then processed to obtain a form of pure metal. Metallurgy also covers the refining of metals, their chemical-thermal treatment, casting and the production of alloys.

The remaining samples of industrial wastewater came from:

- pulp and paper industry. The pre-treated wastewater in the column distillation process is further purified biologically and then discharged into a municipal treatment plant;

- sewage from an inorganic chemistry plant, specializing in the production of rubber mixtures, molded and extruded rubber, anti-corrosive linings, construction chemicals, preparations for chemical metalworking and cleaning preparations;

- wastewater from the textile industry, originating from the processing of natural and synthetic fibers;

- sewage from the mechanical industry, from a plant that uses $\mathrm{CNC}$ machine tools and other mechanical devices in the production processes.

A total of 15 samples of industry wastewater were tested in years 2013/2014.

\section{Toxicological tests}

The assessment of various types of toxic hazards caused by industrial wastewater was made on the basis of acute tests using luminescent bacteria, Daphnia magna crustaceans and Chironomus sp. larvae.
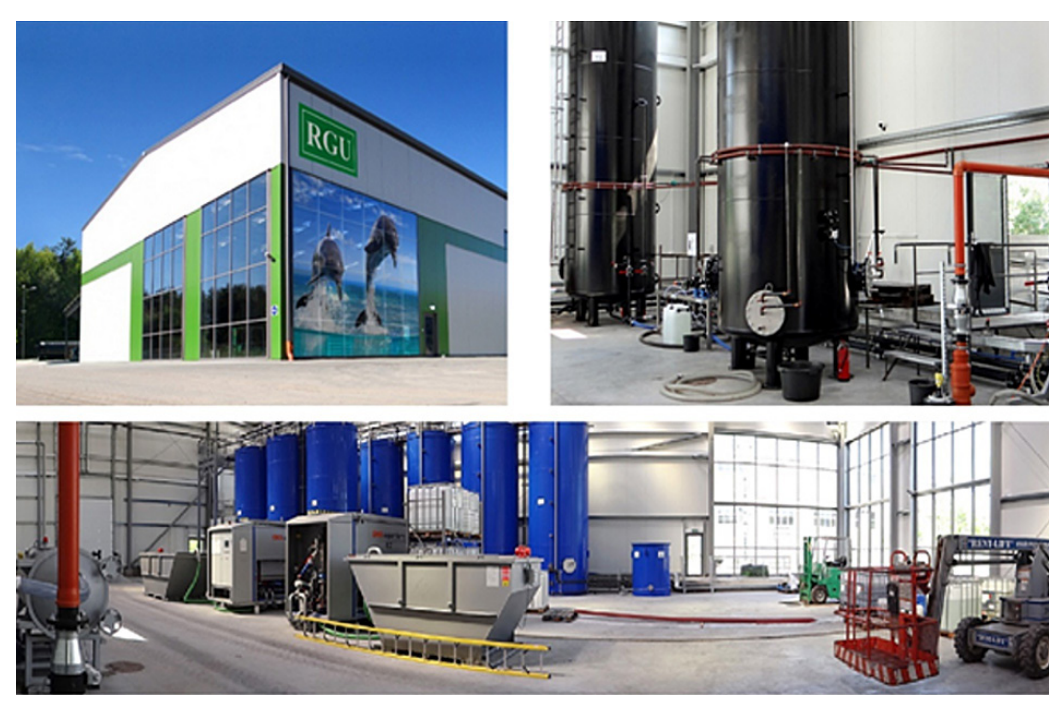

Figure 1. Industrial wastewater treatment plant in Zgierz (Poland) 
Table 1. Wastewater samples obtained from the research facilities

\begin{tabular}{|c|c|c|c|}
\hline \multirow{2}{*}{\multicolumn{2}{|c|}{ Type of industry }} & \multicolumn{2}{|l|}{ Material for research } \\
\hline & & Type of sewage & Mark \\
\hline \multirow{6}{*}{$\begin{array}{l}\text { Industrial sewage } \\
\text { treatment plant }\end{array}$} & \multirow{2}{*}{ galvanic industry } & raw washing waste water & G1 \\
\hline & & treated washing waste water & G2 \\
\hline & \multirow{2}{*}{ mining industry } & waste waters from shale boreholes I & W1 \\
\hline & & waste waters from shale boreholes II & W2 \\
\hline & \multirow{2}{*}{ metallurgical industry } & sewage from processes of skimming & M1 \\
\hline & & sewage from water washing liquids & M2 \\
\hline \multirow{4}{*}{\multicolumn{2}{|c|}{ Pulp and paper industry }} & cellulose sewage & CP1 \\
\hline & & paper sewage & $\mathrm{CP} 2$ \\
\hline & & $\begin{array}{l}\text { sewage from the processing of the waste paper and the } \\
\text { production of the paper pulp }\end{array}$ & CP3 \\
\hline & & $\begin{array}{l}\text { sewage pre-treated at the inflow to the biological sewage } \\
\text { treatment plant }\end{array}$ & CP4 \\
\hline \multirow{2}{*}{\multicolumn{2}{|c|}{ Inorganic industry }} & row waste water & N1 \\
\hline & & treated waste water & N2 \\
\hline Textile industry & & waste water from dyeing processes in dyehouse & F1 \\
\hline \multirow{2}{*}{\multicolumn{2}{|c|}{ Mechanical industry }} & coolant for CNC machine tools - I & P1 \\
\hline & & coolant for CNC machine tools - II & P2 \\
\hline
\end{tabular}

\section{Microtox toxicity test}

The ecotoxicity analysis was carried out in accordance with the PN-EN ISO 11348-3: 2008 standard. The Aliivibrio fisheri luminescent bacteria, previously known as Vibrio fischeri [Urbanczyk 2007], were exposed to various types of industrial wastewater. Aliivibrio fischerii emits light as a result of natural metabolic processes taking place in cells after the contact with the analyzed sewage sample, causing changes in the intensity of light emission by these organisms [Butarewicz 2013].

The luminescence measurement was carried out using Microtox ${ }^{\circledR}$ Model 500 analyzer (Strategic Diagnostics Inc., Newark, USA), based on the manufacturer's procedure - " $81.9 \%$ Basic Test". Before performing the Microtox Basic Test ${ }^{\circledR}$, the samples were appropriately prepared for the assays. The $\mathrm{pH}$ was measured using an HQ40d $\mathrm{pH}$ meter made by the Hach company. The $\mathrm{pH}$ was measured in accordance with the PN-EN 12176 standard. $\mathrm{NaOH}$ or $\mathrm{HCl}$ were used for $\mathrm{pH}$ adjustment to $6-8$. Sodium chloride solution was used to adjust the osmotic pression of the samples to approximately $2 \%$.

Toxicity assessments were made after 5 and 15 minutes. Omni 4.1 supporting computer software with a standard log-linear model was used to calculate the effective concentration values $\left(\mathrm{EC}_{50}\right)$ of the tested samples.

In order to determine the toxicity of industrial waste water samples the calculated values of the
EC50 were converted into units of acute toxicity $\left(\mathrm{TU}_{\mathrm{a}}\right)$ according to the procedure specified for liquid phase calculation:

$$
T U_{a}=100 / L C_{50}
$$

The obtained $\mathrm{TU}_{\mathrm{a}}$ values of the liquid phase were classified into specific toxicity classes according to the criteria presented in the table 2 (Mantis et al. 2005):

\section{Acute toxicity tests using aquatic organisms}

The acute toxicity tests using Daphnia magna crustaceans and Chironomus sp.were used to determine the toxicity of the tested industrial wastewater samples. The toxicity tests were performed using the following recommendations:

The concentrations of industrial wastewater were decreased in geometric progress with the $\mathrm{q}=2$ quotient. Ultrapure water was used to make dilutions. Ten organisms belonging to Daphnia magna and Chironomus sp. species were placed into small glass vessels and appropriate concentrations of the prepared industrial sewage solutions were introduced. the tests were carried out in two replicates for each wastewater sample tested. After 24 hours, the mortality of Daphnia magna crustaceans and Chironomus sp. larvae was observed. The number of dead organisms (not showing any movement reaction) in individual concentrations and types of industrial sewage were noted. Then, the $\mathrm{LC}_{50 / 24}$ value was calculated 
using the computer program. The obtained $\mathrm{LC}_{50 / 24}$ values were converted into acute toxicity units $\left(\mathrm{TU}_{\mathrm{a}}\right)$ according to the formula:

$$
\mathrm{TU}_{\mathrm{a}}=100 / \mathrm{LC}_{50}
$$

On the basis of the obtained $\mathrm{TU}_{\mathrm{a}}$ values and criteria presented in the Table 2, the degree of toxicity of individual wastewater samples were determined.

\section{RESULTS}

Economic development, especially the development of various industries leading to intensive use of the natural environment, enforced the tightening of requirements and control of pollutants introduced into the environment. In many countries, including Poland, the toxicological standards that enable to conduct toxicological tests of sewage and assess the degree of environmental hazard were developed. Unfortunately, there are still no legal regulations that would introduce the obligation to conduct the toxicological tests determining the general toxicity of the discharged sewage. There is also a barrier related to the possibility of conducting toxicological tests of in- dustrial wastewater. In many cases, entrepreneurs are not interested in conducting such research because their results could affect the image of a given industrial plant.

The samples of raw and treated sewage from industrial facilities were subjected to toxicological tests using a Microtox 500 analyzer and the " $81.9 \%$ Basic Test"dilution test. The results of the performed toxicity tests of raw and purified sewage samples from individual industrial plants are presented in Table 3. On the basis of the calculated acute toxicity units of the tested industrial wastewater samples, the appropriate toxicity classes were determined.

Table 2. Toxicity classification system of environmental samples

\begin{tabular}{|c|c|c|}
\hline Toxicity class & TUa & $\begin{array}{c}\text { Evaluation of the } \\
\text { toxicity of the sample }\end{array}$ \\
\hline O & $\mathrm{O}\left(<0,4^{*}\right)$ & no acute toxicity \\
\hline I & $<1$ & low acute toxicity \\
\hline II & $1-10$ & acute toxicity \\
\hline III & $10-100$ & high acute toxicity \\
\hline IV & $\geq 100$ & $\begin{array}{c}\text { very high acute } \\
\text { toxicity }\end{array}$ \\
\hline
\end{tabular}

Source: Mantis et al. 2005 according to the toxicity classification system (TCS) proposed by Persoone (1999). * Katsoyannis and Samara 2007

Table 3. Microtox test results of industrial wastewater samples

\begin{tabular}{|c|c|c|c|c|c|}
\hline \multirow{3}{*}{ Type of industry/number of sample } & \multicolumn{4}{|c|}{ Incubation time [min] } & \multirow{3}{*}{ Toxicity class } \\
\hline & \multicolumn{2}{|c|}{5} & \multicolumn{2}{|c|}{15} & \\
\hline & $\mathrm{EC}_{50}[\%]$ & TUa & $\mathrm{EC}_{50}[\%]$ & TUa & \\
\hline \multicolumn{6}{|c|}{ Galvanic industry } \\
\hline (G1) & 23,4300 & 4,27 & 18,6500 & 5,36 & II \\
\hline$(\mathrm{G} 2)$ & 38,4600 & 2,60 & 42,2500 & 2,36 & II \\
\hline \multicolumn{6}{|c|}{ Mining industry } \\
\hline (W1) & 10,3200 & 9,69 & 9,4480 & 10,59 & III \\
\hline (W2) & 0,2618 & 381,97 & 0,3465 & 288,60 & IV \\
\hline \multicolumn{6}{|c|}{ Metallurgical industry } \\
\hline (M1) & 1,2450 & 80,32 & 0,7478 & 133,72 & IV \\
\hline (M2) & 0,5792 & 172,65 & 0,5481 & 182,45 & IV \\
\hline \multicolumn{6}{|c|}{ Pulp and paper industry } \\
\hline (CP1) & 0,8553 & 116,92 & 0,9103 & 109,85 & IV \\
\hline (CP2) & 28,7900 & 3,47 & 22,0000 & 4,54 & II \\
\hline (CP3) & 16,37 & 6,11 & 16,7200 & 5,98 & II \\
\hline$(\mathrm{CP} 4)$ & 0,4265 & 234,47 & 0,5472 & 182,74 & IV \\
\hline \multicolumn{6}{|c|}{ Inorganic industry } \\
\hline (N1) & 0,4725 & 211,64 & 0,2891 & 345,90 & IV \\
\hline (N2) & - & - & - & - & 0 \\
\hline \multicolumn{6}{|c|}{ Textile industry } \\
\hline$(\mathrm{F} 1)$ & 2,6140 & 38,25 & 2,7470 & 36,40 & III \\
\hline \multicolumn{6}{|c|}{ Mechanical industry } \\
\hline (P1) & 0,4312 & 231,91 & 0,4080 & 245,09 & IV \\
\hline$(\mathrm{P} 2)$ & 0,4302 & 232,45 & 0,4004 & 249,75 & IV \\
\hline
\end{tabular}


The toxicity determination of industrial wastewater, based on the performance of acute tests with Daphnia magna and Chironomus sp., was performed. On the basis of the obtained results of acute tests, the $\mathrm{LC}_{50}$ values were calculated, and transformed into acute toxicity units $\left(\mathrm{TU}_{\mathrm{a}}\right)$. Identification of the tested sewage samples to the appropriate toxicity classes was determined similarly to the Microtox test. The obtained results are presented in Table 4.

\section{DISCUSSION}

\section{Sewage from the galvanic industry}

The Microtox test showed the toxicity of galvanic sewage samples (Table 3 ). The raw rinsing wastewater (G1), which was characterized by acute toxicity, showed greater harmfulness after 15 minutes of incubation. These results were in the range of the results obtained by Soupilas et al. [2008]. They indicated that after 15-minute incubation in each of the 8 samples of galvanic sewage tested, the toxic effect of luminescence droped to $75-100 \%$ and the samples showed significant acute toxicity. Our results revealed the insufficient degree of galvanic sewage treatment after the applied treatment processes as sewage sample (G2) was classified in the second class of toxicity. The toxicity test with aquatic organisms showed a completely different effect of galvanic sewage on the used bioindicators. In the case of purified galvanic sewage (G2), the $\mathrm{LC}_{50 / 24}$ coefficient was not determined for Daphnia magna crustaceans and Chironomus sp. larvae, as the mortality rate was lower than $50 \%$. The sample was assessed as non-toxic in relation to the above-mentioned organisms.

Raw rinsing sewage (G1) showed harmful effects only in relation to the Chironomus sp. and was classified in second class of toxicity.

Rinsing sewage constitutes the majority of the wastewater generated in the galvanic industry. They are characterized by a variable composition and high content of dangerous heavy metals. The degree of toxicity of galvanic sewage depends on the type of raw materials/products used at a given production stage in the technological process of the galvanizing plant [Bartkiewicz and Umiejewska 2010]. The chemical composition of this wastewater can change significantly during the manufacturing process. It should be emphasized that the quality of raw and purified sewage from the galvanic industry was determined with the Microtox test results.

Table 4. Results of an acute toxicity test using aquatic organisms.

\begin{tabular}{|c|c|c|c|c|c|c|}
\hline \multirow{3}{*}{$\begin{array}{c}\text { Type of industry/number of } \\
\text { sample }\end{array}$} & \multicolumn{6}{|c|}{ Acute test } \\
\hline & \multicolumn{3}{|c|}{ Daphnia magna } & \multicolumn{3}{|c|}{ Chironomus sp. } \\
\hline & $\mathrm{EC}_{50}[\%]$ & TUa & Toxicity class & $\mathrm{EC}_{50}[\%]$ & TUa & Toxicity class \\
\hline \multicolumn{7}{|c|}{ Galvanic industry } \\
\hline (G1) & - & - & 0 & 100,00 & 1,00 & II \\
\hline (G2) & - & - & 0 & - & - & 0 \\
\hline \multicolumn{7}{|c|}{ Mining industry } \\
\hline (W1) & 10,15 & 9,85 & II & 34,10 & 2,93 & II \\
\hline (W2) & 2,41 & 41,49 & III & 4,65 & 21,51 & III \\
\hline \multicolumn{7}{|c|}{ Metallurgical industry } \\
\hline (M1) & 5,83 & 17,15 & III & 6,60 & 15,15 & III \\
\hline (M2) & 3,33 & 30,03 & III & 1,46 & 68,49 & III \\
\hline \multicolumn{7}{|c|}{ Pulp and paper industry } \\
\hline (CP1) & - & - & 0 & - & - & 0 \\
\hline (CP2) & - & - & 0 & 100,00 & 1,00 & II \\
\hline (CP3) & 9,43 & 10,60 & III & 22,93 & 4,36 & II \\
\hline (CP4) & - & - & 0 & - & - & 0 \\
\hline \multicolumn{7}{|c|}{ Inorganic industry } \\
\hline (N1) & 0,02 & 5000 & IV & 1,18 & 84,74 & III \\
\hline (N2) & - & - & 0 & - & - & 0 \\
\hline \multicolumn{7}{|c|}{ Textile industry } \\
\hline$(\mathrm{F} 1)$ & 62,09 & 1,61 & II & 37,19 & 2,68 & II \\
\hline \multicolumn{7}{|c|}{ Mechanical industry } \\
\hline (P1) & 2,72 & 36,76 & III & 8,84 & 11,31 & III \\
\hline
\end{tabular}




\section{Sewage from the mining industry}

Drilling wastes are an important group of wastewater generated during shale drilling. Their physicochemical properties depend on the depth and design of the well, the type of drilled rock formations, the drilling technology used, the treatments performed, and above all on the characteristics of the drilling mud used [Starzycka 2012]. Such wastewater is usually characterized by high water content (70\%), various consistency (liquid, semi-solid, slime, ointment), thixotropic structure as well as specific odor and color. Ecotoxicological tests carried out showed a very high degree of harmfulness of sewage from the mining industry in relation to the used bioindicators.

Two types of drilling fluids (sample W1 and W2) originating from shale wells were used. The W2 sample was characterized by higher toxicity in the Microtox test and was thus classified in the fourth class of toxicity. In the case of the test with aquatic organisms, a sample of W2 wastewater was classified as highly toxic (third class of toxicity). The wastewater from the mining industry contains many harmful impurities, such as suspended solid phase (cuttings), loading materials (barium sulphate, calcium carbonate, iron ore), heavy metals (lead, chromium, cadmium), or petroleum substances (fats, oils, lubricants) [Starzycka 2012, Zima 2012]. Their high toxic effect is primarily influenced by the chemical additives found in drilling fluids, which was confirmed by Zima [2012]. They tested Aliivibrio fischeri and observed a very high toxicity of the PHPA type polymers, polyglycols, liquefaction agents, i.e. tannins and lignosulphonates, and biocides. Only the protective colloids $\left(\mathrm{K}_{2} \mathrm{SO}_{4}, \mathrm{KCl}\right.$, and HCOOK) were characterized by low toxicity or its lack. They also pointed out the significant usefulness of bioindicative tests in assessing the toxicity and monitoring the impact of drilling fluids on the natural environment.

\section{Sewage from the metallurgical industry}

The toxic effect of wastewater from the metallurgical industry is caused primarily by various heavy metals $(\mathrm{Fe}, \mathrm{Pb}, \mathrm{Zn}, \mathrm{Cu})$ present in their composition. These elements may come from the production of pig iron and steel, steel processing, rolling processes, hydro-piercing, cleaning of castings and many others. The tested sewage samples from the metallurgical industry were characterized by a significant degree of toxicity.
The Microtox test showed that both wastewater from degreasing processes (M1) and aqueous washing liquids (M2) were characterized by very high acute toxicity and thus classified into class IV toxicity. The high harmfulness of metallurgical sewage from degreasing processes may be caused by such substances as chlorinated derivatives (trichlorethylene, tetrachlorethylene), aromatic hydrocarbons, alkalis, surface active agents (SPC), corrosion inhibitors, complex-forming compounds, antibacterial agents. The post-production liquids from the degreasing process usually require purification by neutralization and coagulation [Institute of Precision Mechanics 2009; Bartkiewicz and Umiejewska 2010].

In the case of the test with aquatic organisms, the sewage samples from the metallurgical industry were characterized by a similar toxicity (III class) in relation to the used bioindicators. Waterborne cleaning liquids (M2) showed greater harmfulness. The aqueous washing liquids are the wastes in the form of a water solution with a cleaning agent. They are created in the process of washing details, most often carried out during metalworking. Washing baths, or the sewage discharged into the sewage system, pose a significant threat to municipal sewage treatment plants, as they are classified as hazardous waste. The water washing liquids are usually cleaned in physicochemical processes, using specialized installations enabling the precipitation of heavy metals and removal of other toxic substances [Majka 2007].

\section{Sewage from pulp and paper industry}

The cellulose and paper sewage contain lignin compounds of high durability and low biodegradability in their composition. Additionally, they may contain the substances which are toxic to aquatic organisms, i.e. resin acids, organochlorine compounds (mainly chlorophenols), dyes, biocides, surfactants, biocides, salts, detergents, peroxides, sodium persulfate, chelating agents.

The toxicological analysis evaluated the toxicity of 4 sewage samples from the pulp and paper industry, which constituted the sewage from cellulose pulp production (CP1), paper sewage (CP2), sewage from processing of waste paper (CP3) and sewage on the inflow to the biological sewage treatment plant (CP4), respectively. The obtained results showed a varied impact of wastewater samples on the used bioindicators.

On the basis of the Microtox test, the sewage from pulp production (CP1) and the sewage 
on the inflow to the biological sewage treatment plant (CP4) were classified in the fourth class of toxicity, i.e. to a very severe toxic hazard. The risk associated with introducing the pre-treated sewage to the second stage of biological treatment in the activated sludge chambers was of particular importance. The pre-treated sewage was a mixture of technological wastewater (from each production stage) and domestic sewage. The high degree of toxicity is mainly affected by the sewage from technological processes, while the domestic sewage being a specific solvent contributes to the reduction of general toxicity.

The wastewater from the waste paper processing showed a significantly lower toxicity. They were qualified to the second class of toxicity, i.e. to the sewage constituting a severe threat. In the case of the paper wastewater after 15-minute incubation with Aliivibrio fischeri, the highest sample concentration caused a reduction in the produced light by $71.83 \%$. A similar result was obtained by Soupilas et al. [2008], who tested 3 samples of wastewater from paper production. The cited authors determined the decrease in Aliivibrio fischeri luminescence bacteria in the range of $30-70 \%$.

The sewage from the pulp and paper industry showed much lesser toxicity in relation to the tests carried out with Daphnia magna crustaceans and Chironomus sp. larvae. In the case of the samples of cellulose effluents and the sewage flowing into a biological sewage treatment plant, the $\mathrm{LC}_{50 / 24 \mathrm{~h}}$ parameter was not determined because the mortality rate of the used bioindicators was lower than $50 \%$. The highest toxicity in relation to aquatic organisms was characterized by the sewage from the processing of waste paper. On the basis of the test results with crustaceans, the sewage was characterized by acute toxicity (III class), but in the test with Chironomus larvae, the wastewater was classified in the second class. Verma [2010] found a slightly higher toxicity by studying the acute toxicity of pulp and paper sewage with the use of Daphnia magna. The cited author analyzed 5 samples, 4 of which showed acute toxicity.

It should be emphasized the Microtox test proved to be the most sensitive and determined the final toxicity of wastewater.

\section{Sewage from inorganic industry}

Toxicological tests were carried out on raw sewage $(\mathrm{N} 1)$ and treated wastewater $(\mathrm{N} 2)$ from an inorganic industry specializing mainly in the production of rubber products. In the Microtox test, the raw sewage sample showed very acute toxicity and was classified in the fourth class of toxicity. The $\mathrm{EC}_{50 / 15 \min }$ parameter for raw wastewater was only $0.2891 \%$. Extremely high toxicity of raw sewage from the inorganic industry was also found in relation to aquatic organisms. The N1 sample was classified with Daphnia magna into the fourth class of toxicity (extremely toxic wastes). Similar research carried out by Yi et al. [2011] also showed very high acute toxicity of the sewage from the rubber factory in the Daphnia magna test. On the basis of the performed tests, the quoted authors determined that the main cause of toxicity of this kind of post-production liquids were the accelerators containing zinc compounds used in vulcanization processes.

The wastewater treated (N2) from the inorganic industry showed no toxicity with regard to the used bioindicators. The obtained results of the carried out toxicological analyzes indicate the proper operation of the treatment plant and chemically harmless sewage outflow to the receiver.

\section{Sewage from textile industry}

The results of toxicological tests of raw sewage from the dye-works of the textile industry (F1) showed differential toxicity with regard to the used bioindicators. The tested wastewater sample in the Microtox test showed high acute toxicity and was classified in the third class of toxicity. In the case of a test with aquatic organisms, the wastewater from the dye-works was more harmful to Chironomus sp., than for Daphnia magna. The wastewater sample from the textile plant was classified to the second class of toxicity (toxic sewage). Similar research was carried out by Verma [2011] who used Daphnia magna crustaceans to assess the toxicity of acute stained textile wastewater. The cited author analyzed seven samples, three of which showed toxic effect. Dyes and detergents are primarily responsible forthe toxicity of sewage from the dye works of the textile industry for. These substances are resistant to biodegradation and give the wastewater a specific and intense color. Their quantity in post-production liquids depends on the dyeing method, the type of colored raw material, and the type of dye [Bilińska et al. 2012, Greluk 2013].

\section{Sewage from mechanical industry}

Two samples of cooling fluids (P1, P2 Statoil ToolWay E 655) used for cooling CNC machine tools were subjected to toxicological 
analysis. The research material differed in its use time. According to the safety data sheet, a clean unused liquid is harmless to living organisms.

On the basis of the tests carried out, the samples of the spent cooling fluid were classified to the highest class of toxicity (IV - very high acute toxicity). The toxic properties can result from the use of cooling liquids in machine processes, during which they come into contact with many hazardous substances. The toxicity of P1 and P2 fluid samples obtained in the Microtox test was compared to one sample of coolant - P1 in the test with aquatic organisms. The greater harmfulness of the P1 sample was showed with reference to the Daphnia magna crustaceans and to the Chironomus sp. In the case of both bioindicators, the P1 fluid sample caused significant toxic effects and it was classified to the third toxicity class (highly toxic wastes).

\section{CONCLUSIONS}

1. The bioindication analysis showed different toxicity of post-production sewage. In particular types of sewage, a strong dependence of the toxic effects on their character was found, which was as an effect resulting from raw materials, products and auxiliaries used in the operations of individual industrial plants.

2. The highest toxic effects for all of the bioindicators used, i.e. Aliivibrio fischeri, Daphnia magna crustaceans and Chironomus sp., were obtained in the case of raw wastewater from the inorganic industry and wastewater from the mining and metallurgical industries.

3. Bioindication methods do not enable to identify the types of substances responsible for toxicity; therefore, the presented interpretation of the results indicated only the most important chemicals that could potentially affect the harmfulness of industrial wastewater. Therefore, when analyzing industrial wastewater samples, it is advisable to use the biotests involving organisms belonging to different levels of the trophic chain. Studies have also shown that bioindicator reactions can be one of the main ways for determining the biological effects of chemical substances.

4. In the toxicological analysis, the Aliivibrio fischeri bacteria were characterized by the highest sensitivity; therefore, the Microtox test determined the final toxicity for almost ev- ery type of industrial wastewater. The Microtox system is increasingly used in wastewater treatment plants for monitoring the incoming effluent. This type of control consists in a continuous analysis of the main streams of sewage affecting the area of a particular facility. In the first stage, the level of toxicity at which the purification processes are carried out is determined. Then, their exceedances can be identified based on the registered toxicity levels of the waste water streams [Nałęcz-Jawecki 2006]. Both in the case of raw sewage and treated wastewater, the Microtox test result is a reference point for undertaking the activities aimed at elimination of hazardous substances in the treatment process as well as in the environment.

\section{Acknowledgements}

This work was financially supported by research project number S/WBiIŚ/3/2015.

\section{REFERENCES}

1. Bartkiewicz B., Umiejewska K. 2010. Purification of industrial wastewater, Scientific Publisher PWN, Warsaw. (in Polish)

2. Bilińska L., Bemska J., Biliński K., Ledakowicz S. 2012. Integrated chemical-biological treatment plant of textile sewage, Engineering and chemical apparatus, No 4, 95-97. (in Polish)

3. Butarewicz A. 2013. Monitoring of municipal wastewater treatment plant using the Microtox set, Economics and Environment, No 4 (47), 187-198. (in Polish)

4. Greluk M., 2013. Use of ion exchangers, ion exchange membranes, polymeric sorbents and biopolymers in removal of acid and reactive dyes from aqueous solutions. Chemical industry, No 4, 469-478.(in Polish)

5. Institute of Precision Mechanics, Best Tech Access (BAT). Guidelines for surface treatment of metals and plastics, Warsaw. 2009. (in Polish)

6. Katsoyiannis A., Samara C. 2007. Ecotoxicological evaluation of the wastewater treatment process of the sewage treatment plant of Thessaloniki, Greece. Journal of Hazardous Materials, 141, 614-621.

7. Majka M. 2007. Cleaning liquids from surface treatment of metals, Recycling. Vol. 82, No 11, 14-15. (in Polish)

8. Starzycka A., Environmental and legal aspects of the management of waste generated during the ex- 
ploration, identification and extraction of shale gas. Polish Geological Institute - National Research Institute, Poznań 2012. (in Polish)

9. Mantis I., Voutsa D., Samara C. 2005. Assessment of the environmental hazard from municipal and industrial wastewater tratment sludge by employing chemical and biological methods. Ecotoxicology and Environmental Safety. 62, 397-407.

10. Nałęcz-Jawecki G., 2006. Quality assessment of raw sewage. Water supply and sewage. Vol 34, No 12.

11. PN-EN ISO 11348-3:2008 Water quality. Determination of the inhibitory effect of water samples on light emission by Vibrio fischeri (study on luminescent bacteria). Part 3: Method using lyophilized bacteria.

12. Richardson S.D., Kimura S.Y. 2017. Emerging environmental contaminants: Challenges facing our next generation and potential engineering solutions. Environmental Technology \& Innovation. Vol. 8,40-56.

13. Richardson, S.D., Ternes, T.A. 2011. Water analysis: emerging contaminants and current issues. Anal. Chem. 83, 4614-4648.

14. Richardson, S.D., Ternes, T.A. 2014. Water analysis: emerging contaminants and current issues.
Anal. Chem. 86, 2813-2848.

15. Soupilas A., Papadimitriou C.A., Samaras P., Gudulas K., Petridis D. 2008. Monitoring of industrial effluent ecotoxicity in the greater Thessaloniki area. Science Direct, No 224, 261-270.

16. Urbanczyk H., Ast J.C., Higgins M.J., Carson J., Dunlap P.V. 2007. Reclassification of Vibrio fischeri, Vibrio logei, Vibrio salmonicida and Vibrio wodanis as Aliivibrio fischeri gen. nov., comb. nov., Aliivibrio logei comb. nov., Aliivibrio salmonicida comb. nov. and Aliivibrio wodanis comb. nov. International Journal of Systematic and Evolutionary Microbiology, 57(12), 2823-2829.

17. Verma Y., 2011. Toxicity assessment of dye containing industrial effluents by acute toxcity test using Daphnia magna, Toxicol Ind Health, Vol. 27, No 1., 41-49.

18. Yi X., Kim E., Jo HJ., Han T., Jung J. 2011. A comparative study on toxicity identification of industrial effluents using Daphnia magna, Bull. Environ. Contam Toxicol, 87, No 3, pp. 319-323.

19. Zima G., 2012. The use of bioindication methods to assess the toxicity of chemical agents used in drilling mud compositions, Oil and Gas, No 2, 115-122. (in Polish) 